\title{
3.2 \\ TRÄ, TEXTIL OCH PAPPER \\ SOM UNDERLAG
}

\author{
Ingalill Nyström, ${ }^{108}$ Liv Friis, $^{109}$ Johan Knutsson ${ }^{110}$ \\ och Anneli Palmsköld ${ }^{111}$
}

Detta kapitel fokuserar på underlaget som material och teknik i inredningarnas måleri och mönstrade textilier i Hälsingland. Hantverkaren gör sitt materialval beroende på tillgång, ekonomi, miljö, konventioner och kunders efterfrågan. Det tidiga väggmåleriet under 1700-talet var framför allt utfört på trä eller textil. Under tidigt 1800-tal introducerades även papper som underlag. Trä av olika slag utgör även underlag för bemålningen av möbler. Inredningstextilierna kunde vara tillverkade i olika material och tekniker och den bottenvävda textilen kunde utgöra underlag för dekorationer och mönster i andra tekniker.

De olika underlagsmaterialen beskrivs här mer i detalj utifrån egenskaper, tekniker och hantverkares kunskaper. Störst fokus kommer att ligga på papper som underlag eftersom en separat fallstudie om detta har genomförts i projektet. Kapitlet avslutas därför med en detaljerad beskrivning av de olika moment som ingår i hantverksmässig papperstillverkning.

\section{Underlag i interiörmåleri}

Det tidiga väggmåleriet i Hälsingland under 1700-talet var utfört på trä eller textil. Träunderlaget utgjordes framför allt av den slätbilade, timrade furuväggen i stugan. Även trälister och -paneler i furu har ut-

108. Ingalill Nyström har bidragit med kunskapen om trä, textil och papper som underlag för måleri.

109. Liv Friis har gjort fallstudien om papper i Hälsingland.

110. Johan Knutsson har bidragit med delen om trä som underlag och möbler.

111. Anneli Palmsköld har bidragit med kunskap om textil som material i inredning. 
gjort underlag i måleri. Då textil förekommer som underlag i området är det oftast ny väv som använts. I enstaka fall finns också exempel på återanvänd textil som underlag. I Sydsverige var återanvända textilier som underlag i folkliga sammanhang mycket vanligt (Nyström 2012). Textilunderlaget var vanligtvis av lin vävt i tuskaft, ibland också fiskben eller kypert. Textilien spändes upp direkt mot timmerväggen för att sedan bemålas. Vid måleri på textil förekommer också en grövre, tätare kvalitet av linne, ibland i jute eller hampa. Ibland rör det sig om en så kallad buldansväv, det vill säga en grov vävnad i tuskaft, vävd av linne, hampa eller jute. Under 1800-talet användes ibland tidningspapper som värmeisolering mellan textil och timmervägg samt för att skapa ett jämnare underlag. Under denna period kan väggmåleriet även vara utfört på papper, troligen av typen makulatur. Ibland är pappret uppspänt med nubb, i andra fall har det fodrats upp och limmats fast, mot en glesvävd textil för att hålla samman bättre vid byggnadens eventuella rörelser.

Underlag av trä, textilier eller papper för väggmåleri har ibland förbehandlats med ett lim innan det har grunderats och sedan bemålats. Denna typ av förbehandling kallas för isolering och har funktionen att den mättar och fixerar de porösa och hygroskopiska fibrerna, vilket gör att vattenlöslig grundering fäster bättre. Grunderingen i sin tur fungerar som reflektor och behövs också för de magra färgernas skull. Oljemålade trälister har sällan grunderats eller isolerats. Fet oljefärg suger in och fäster bra mot det porösa träunderlaget.

I undersökningen av inredningsmåleriet har flera exempel på glesvävd tuskaft i linne, en så kallad entränning, påträffats. Väven utgör ofta underlag för tapeter och måleri på papper. På världsarvsgården Bommars finns ett rum inklätt med denna väv (se fig. 1). Väven har spänts upp och förberetts med fastlimmat tidningspapper. Av någon anledning har rummet sedan förblivit obemålat. Huruvida produktionen av dessa glesa vävar bara gällde Hälsingland eller om de även såldes och användes på andra platser är okänt.

En viktig del av hantverkarens kunskap handlade om vilka egenskaper olika material har och hur de fungerar var för sig och tillsammans samt i olika hantverkliga kontexter. Ett exempel på detta är att lin krymper vid fuktning, men expanderar och tänjs ut vid torkning. Dessa egenskaper har hantverkaren förhållit sig till och varit medveten om vid uppspänning av väv. I traditionellt måleri, framför allt stafflimåleri, spänns duken om ett antal gånger tills fibrerna har ordnat sig och slapp- 
Figur 1 (3.2.1): En glesvävd linnevävnad, entränning, som förberetts för måleri på världsarvsgården Bommars. Foto: Ingalill Nyström

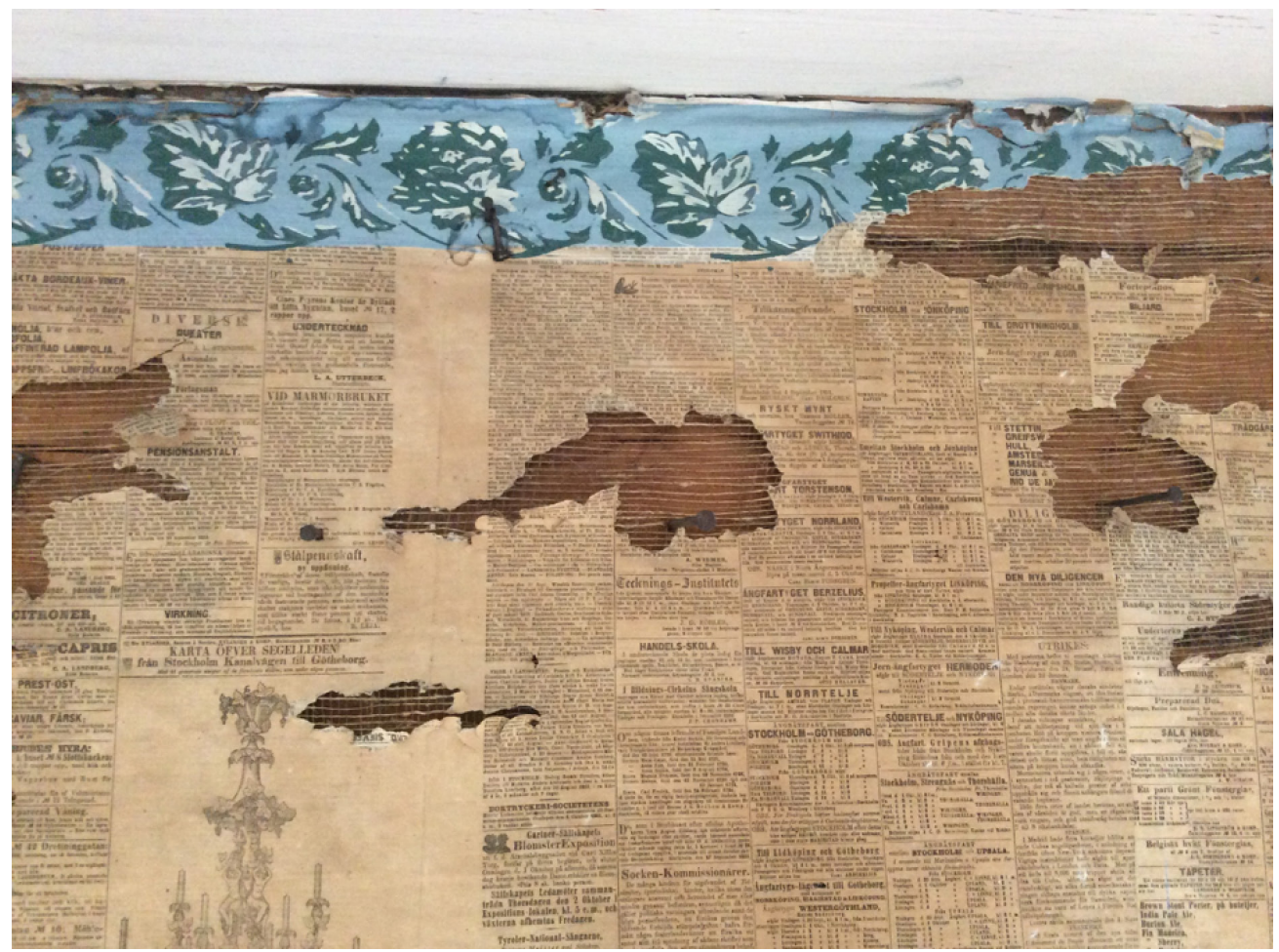

nat av. Vid den sista uppspänningen isoleras duken med limlösning som fixerar och låser fibrerna. I inredningssammanhang har momenten av upprepad uppspänning hoppats över och fixeringen kan ha gjorts direkt med hjälp av lim. I sydsvenskt bonadsmåleri har stärkelselim ibland använts, vilket troligen även har förekommit i Hälsingland. Möjligen kan också tvättad textil ha använts som underlag eftersom det slappnat av och rör sig mindre, det vill säga att fibrerna efter upprepad tvätt är mindre krymp- och svällningsbenägna.

Hantverkaren har kreativt försökt lösa sin uppgift på ett tidsbesparande sätt, utan att alltför mycket äventyra resultatets kvalitet. De djupa kunskaperna om materialens olika egenskaper och användningsområden var användbara vid tillverkning och nyttjande av materialen samt vid skötseln av de målade ytorna.

\section{Trä som material i möbler}

Tillverkningen av möbler har genom historien varit beroende av materialet trä. Trä är ett levande och hygroskopiskt material som rör sig vid fukt- och temperaturfluktuationer. Dessa egenskaper påverkar hur möbler konstrueras och fogas samman. Skilda tillverkningstekniker och -processer kräver olika verktyg beroende på träslagets hårdhet, 
porösitet och bearbetningsbarhet. Träslagens varierande egenskaper gör dem mer eller mindre lämpade för olika ändamål.

Ask och idegran kan användas i tunnare dimensioner än furu, utan att knäckas vid belastning. Bok låter sig böjas, basas, med hjälp av värme och ånga. Ek och alm är särskilt slitstarka och tåliga träslag, motståndskraftiga mot skadeinsekter och röta. Lind, ek, al, asp och björk lämpar sig för skulptur, som skurna möbelornament. Lind är mycket mjukt och lättbearbetat och tillåter skuret arbete på extrem detaljnivå. Barrträ, liksom lövträ som al, björk och ek har varit vanliga träslag för stolar, särskilt stolar i sargkonstruktion. Ibland har flera träslag blandats i en och samma möbel, med till exempel stolpar i furu, sits av ek och skurna detaljer i björk eller lind.

Furu och gran har hört till de vanligaste materialen för möbeltillverkning i Sverige - främst i folkliga sammanhang. De har använts för att de har varit de mest tillgängliga. Furu är mer kvistfritt än gran och därmed lämpligare för flera ändamål eftersom kvistar lämnar spår i virket. Ur dem kan kåda sippra fram och de kan falla ur när träet torkar. I norra Sverige är virket tätvuxet på grund av långsam tillväxt i det kallare klimatet, vilket gör materialet mer tåligt, motståndskraftigt mot angrepp och lämpligt för både konstruktion och utfyllande partier. Även om lövträslag generellt lämpar sig bättre för skuren dekor har barrträslag använts för skulpterade möbeldetaljer med förvånansvärt stor precision. Furu har sällan exponerats som obehandlad yta, utan vanligen bemålats eller på olika sätt ytbehandlats för att framstå som något annat, mer exklusivt och åtråvärt träslag eller material.

I möbelmåleriet finns vissa generella principer för val av målarmaterial och komposition av motiv och mönster, val som i sin tur har med underlaget och möbelns konstruktion att göra. Förvaringsmöbler, som skåp och kistor, erbjuder plana ytor lämpade för målad dekor. Dessa möbelkategorier, liksom golvur och skrin, hör till de statusfyllda allmogemöbler som brukar vara praktfullt bemålade. I Hälsingland har vi därutöver även att räkna med de för området typiska mössborden, en kombination av förvarings- och bordsmöbel, och de för festmåltiden avsedda långborden med dess målade bordsskivor. I jämförelse med det arkitekturbundna interiörmåleriet är de inom möbelmåleriet till buds stående obrutna ytorna ändå begränsade. De berättande figurscenerna saknas nästan helt. Fokus ligger istället på ornamentiken, ofta abstrakt, stiliserad och vanligen strikt symmetrisk. Hos ett målat skåp är möbelns konstruktion framhävd, inte dold, genom betoningen av 
ramverk och fyllningar (dörrspeglar), med profilerna runt dörrspegeln målade i en avvikande färg. Oljefärgen är ofta tunt pålagd, sällan pastost och flödigt. Oftast saknas grundering. Målaren tycks inte ha haft några problem med att måla på ett underlag som kunde vara både ojämnt och defekt genom kvistar och spånutslag i ytan.

\section{Textil som material i inredning}

I Hälsingland förekom en omfattande linodling och linnevävning, både för eget bruk och för försäljning (Fiebranz 2002:24, 84ff). Under 1700- och 1800-talen var tillverkningen specialiserad. I den södra delen såldes skäktat och berett lin och i den norra grövre vävnader som buldansväv, foderväv och bolsterväv (Nylén 1995:129) samt även segelduk (Fiebranz 2002:105). Den inhemska efterfrågan på grov linneväv ökade under 1700-talet på grund av krig och växande handel (ibid.). Produktionen gällde segel, tält och uniformer. Med andra ord pågick en omfattande produktion av lin, som även användes i inredningssammanhang som underlag till måleri och till bland annat gardiner, mattor, sängkläder och handlakan.

Själva linberedningen var mycket arbetskrävande, vilket också gäller spinningen och tvinningen av garnerna. Det behövdes tre till fyra spinnerskor för att försörja en väverska med material (Nylén 1995:118). Genom nyodling i Hälsingland och den allmänna befolkningstillväxten ökade tillgången till lin (Fiebranz 2002:106). Även teknisk utveckling bidrog till att linproduktionen ökade fram till 1820-talet. Detta tack vare innovationer som vattendrivna linbråkor och linskäktor som byggdes under 1700-talets andra hälft (Nylén 1995:116f; Fiebranz 2002:105f).

Mot slutet av 1700-talet fick linet konkurrens av bomullen, genom import via England. Detta var ett nytt material som nu blev tillgängligt i västvärlden genom tidens kolonialism och slavhandel (Palmsköld 2017:31; Yafa 2006; Lemire 2011). Bomull blev ett oerhört populärt material. ${ }^{112}$ Det lämpade sig väl för att färga in i klara färger som till exempel rött, se kapitel 3.3 Färgers framställning, distribution och användning. Vejde, turkiskt rött och andra färger. Garn och tråd kunde färgas in och användas till vävnader i olika färger och mönster eller till broderier och

112. Ett exempel på bomullens popularitet är att den brittiska konsumtionen av råbomull 50-dubblades mellan åren 1770 och 1830 (Nyberg \& Lundqvist 2013:12). 
spetsar. Tyger i bomull kunde användas som underlag för mönstrade tryck, som till exempel de kattuner som blev oerhört populära i det folkliga modet.

Exakt hur det gick till när befolkningen i Sverige började använda bomull som material, är oklart även om bevarade textilier i viss mån kan hjälpa till att belysa frågan. Klart är att de inhemska mekaniserade bomullsspinnerierna som anlades, blomstrade under 1800-talets första hälft och att 1830-talet räknas som det decennium då bomull fick sitt stora genombrott (Nyberg \& Lundqvist 2013:12). Råbomull importerades från Amerika och England. Först kom importen via Stockholm, för att senare flyttas till Göteborg för att möta efterfrågan från den tidiga textilindustrin i Västergötland (Nylén 1995:112). De upparbetade handelsvägarna mellan Hälsingland och Stockholm indikerar att materialet tidigt blev känt och använt i inredningstextilier och i klädedräkt. Till exempel såldes importerat turkrött garn i bomull i handelsbodar i början av 1800-talet (Olof Perssons arkiv). Men även om linet fick konkurrens fortsatte produktionen i mindre skala.

Lin och bomull är de material som dominerar i inredningstextilierna, även i golvmattor, gardiner och rullgardiner. ${ }^{133}$ Ull förekommer också, främst i täcken som användes på bord och sängar. Ryor i flossateknik med mönster i olika färger lades på sängar. Opphämtatäcken användes till bord. Dessa täcken var i vissa fall inköpta av västgötaknallar, i andra fall tillverkade lokalt (Lundqvist 2008). Vissa golvmattor trycktes i stora mönster i två färger och även trasmattor och ripsmattor förekommer.

I vissa bevarade inredningstextilier förekommer både lin och bomull samtidigt. Exempel på detta är röda broderier i bland annat korsstygn, stjälkstygn och tofssöm. De syns både i monogram och årtal samt i abstrakta och föreställande mönster på kuddvar, hänglakan och handkläden. I täcken vävda i trasväv samsas små, klippta remsor i små "knippen" som vävs in och bildar mönster mot en ljusare, enhetligt färgad botten. Här finns exempel på stickad ylletrikå i rött, svart och blått, remsor av tryckta bomullskattuner samt blåfärgade rester av kypertvävda arbetskläder som har återanvänts. Vissa handkläden vävda i tuskaft eller kypert avslutas med en bred bård vävd i rosengång, där rött bomullsgarn bildar ränder som dominerar över det vita bomullsgarnet.

113. Materialkaraktärisering av fibrer i inredningstextilier har inte genomförts inom ramen för projektet. Det är möjligt att även material som hampa och jute förekommer (jfr Skoglund 2016). 
De spetsar som förekommer på kuddvar, hänglakan och handkläden är utförda i olika slags tekniker, som knyppling, språngning och virkning, ofta med inslag av rött bomullsgarn som bildar mönster.

Textilhantverkare hade kunskap om materialens egenskaper och om vilka material och tekniker som bäst samspelade. För att bibehålla styrkan kunde en väverska lägga en fuktig duk över linnevarpen under vävprocessen. Lin blir starkare när det är fuktigt, men bryts lätt i torrt tillstånd särskilt när det är nytt och otvättat. Ull användes för sin mjuka och värmeisolerande förmåga och förekommer därför som sängtäcken. Materialet innehåller naturliga fetter som lanolin, och fibrernas ytliga fjäll gör att de hakar i varandra och kan skapa en porös, luftig och fluffig struktur med isolerande egenskaper. Bomullens mest eftertraktade egenskap, förutom att den gick att färga med klara färger, är att den kan blekas till kritvita nyanser som får färger i mönster, dekor och broderier att framstå som än starkare. Materialet är också starkt och hållbart på grund av fiberns spiralstruktur.

\section{Papper som material i underlag, mallar och schabloner}

Pappret som användes som underlag i hälsingemåleriet har med stor sannolikhet producerats lokalt. ${ }^{114}$ Pappersbruken i området grundades huvudsakligen under senare delen av 1700-talet och framåt. I Sverige började papper att tillverkas först under 1500-talet (Rudin 1987). De första pappersbruken låg framför allt i södra Sverige. Dessförinnan importerades papper från Europa, som användes som skrivpapper. Pappret var länge ett exklusivt och dyrt material, något som ändras först under 1800-talet (ibid.).

\section{Tillgången påpapper}

Det krävdes kungligt tillstånd för att få anlägga en papperskvarn och för att få samla in linnelump, som utgjorde basen för papperstillverkningen. Linnet användes som råmaterial till papperspulpen, även kallad mäld. Pappersbruken engagerade särskilda lumpsamlare som reste runt och samlade upp textillump från allmogen. Lump betraktades som en

114. Detta kan styrkas genom brukens relativt stora produktion av papper samt närheten till orter där hantverkarna köpte material. Papper som underlag i hälsingemåleriet beskrivs i utställningen Bild på bondevägg 1996 (Lundell \& Sinha 1996). 


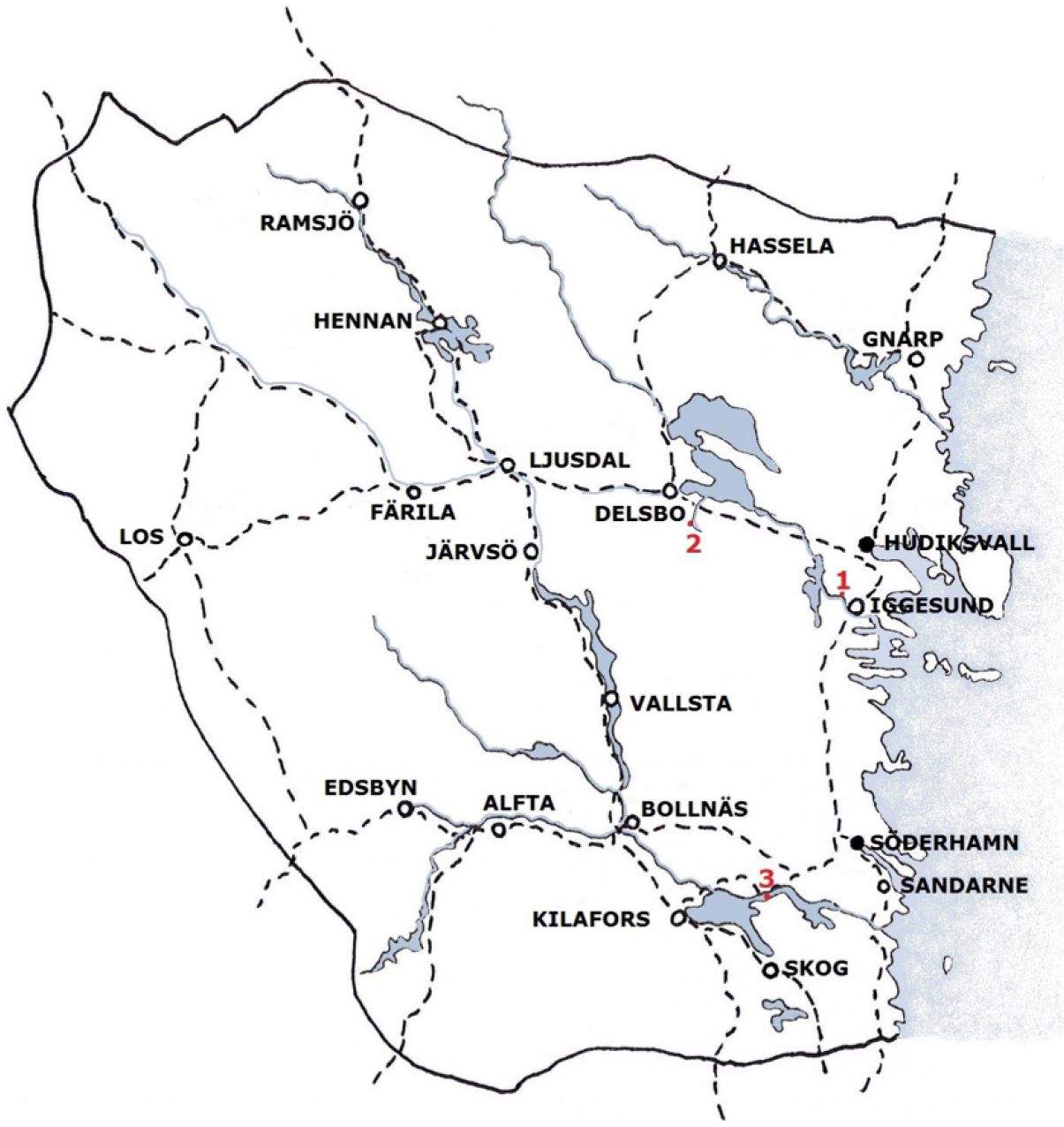

bristvara då det var svårt att få folk att vilja lämna ifrån sig detta råmaterial. Därför organiserades lumpinsamlingen av staten kring 1700-talets slut. I början av 1800-talet kunde pappersbruken ansöka om privilegiebrev och på så vis få rätt att byta till sig lump från lumpsamlare i trakten (Bringéus 1999:62). Det är också då som pappret blir billigare att tillverka tack vare mer tillgänglig lump, men även på grund av teknikutveckling.

I södra Sverige låg pappersbruken tätt, det fanns cirka 65 pappersbruk i det sydsvenska bonadsområdet under åren 1700-1870 (Nyström 2012:88). I Hälsingland under samma period var det bara några få bruk verksamma (se fig. 2). Skillnaden beror på tillgången till lump, som var betydligt större i det tätbefolkade Sydsverige. Utöver tillgången på material var brukens placering beroende av vattentillgång och vattnets fallhöjd, eftersom vattnet användes som renings- och kraftkälla.

Ett tidigt exempel på pappersbruk i Hälsingland är Östanå bruk vid
Figur 2 (3.2.2): Karta över Hälsingland med vissa vattendrag, vägnät och orter ungefärligt angivna utifrån generalstabskartor från 1800-talets mitt.

1) Östanå pappersbruk, Iggesund

2) Fredriksfors pappersbruk, Delsbo och 3) Bergviks pappersbruk, mellan Kilafors och Söderhamn. Av kartan framgår hur bruken placerats utifrån geografiska förutsättningar såsom vattendrag, fallhöjd och närhet till transportvägar. Karta: Liv Friis 
Iggesundsbukten som startades 1665 och som fick ensamrätt på lumpinsamlingen i Norrland 1672 (Bergström 1981:10). Ett annat pappersbruk var det lilla bruket vid Klubboån i Delsbo, som nämns 1736 och som då ägdes av Knut Nilsson Lenæus. Det var dock först 1845 som ett riktigt pappersbruk anlades på platsen (Valeur 2007:25). Bruket fick då namnet Fredriksfors efter den dåvarande ägaren Fredrik Hofverberg och tillverkade framför allt omslagspapper och papp av grövre lump. Vidare fanns Bergvik bruk, verksamt mellan åren 1798 och 1855 (ibid. 2007: 139). Bruket var beläget vid Bergviksströmmen en dryg mil från Ljusnans utlopp. Det startades av Johan Brolin och Eric Albrect Stenfelt, som båda var delägare i Flors Linne Fabriques Bolag, känt som Flors linnemanufaktur. ${ }^{15}$ År 1733 fick manufakturen privilegier och kunde därmed anlägga en papperskvarn. Det blev då möjligt att återanvända det linne som annars skulle kastas. På så sätt var tillgången till råmaterial säkrad. Kvarnen uppfördes dock först 1798 vid Ljusnan. Söderhamns Hallrätt kontrollerade verksamheten den 31 mars 1802 och det noterades då att pappersbruket tillverkade åtskilliga sorters papper (Bergström 1981:19). Året dessförinnan finns uppgifter om 13 anställda som ska ha tillverkat 1510 pappersark av olika slag. Produktionskapaciteten var hög tack vare den kyp som verksamheten ägde. Några år senare, 1805, då ytterligare en kyp satts in, dubblades brukets kapacitet till 3045 pappersark. Detta utan att antalet anställda behövde ökas.

Runt 1800-talets mitt började pappersbruken använda annat råmaterial än lump. Massaframställning av trä blev då mer vanligt. Norrland hade därmed plötsligt bättre förutsättningar än södra Sverige, varför också Hälsinglands pappersproduktion ökade. Jonas Stakel, verksam vid Östanå bruk 1735 och framåt, kom att bli en pionjär vad gäller tillverkningen av papper med träfiber. Han omnämns av Vetenskapsakademin redan 1751 för att ha lyckats tillverka ett papper enbart av träfibrer. Det dröjde dock nästan ett sekel innan papper började framställas av trämassa i stor skala och med hjälp av långduksmaskiner.

Det papper som användes i interiörmåleriet i Hälsinglands gårdar var ett oblekt lumppapper, så kallad makulatur, tillverkat i större ark, cirka 50 gånger 60 centimeter (jfr Nyström 2012:86f). Dessa pappersark var billigare att tillverka än skrivpapper av vit, blekt linnelump. Vattenstämplar och vattenmärkning användes för att kvalitetsstämp-

115. För mer information om linnefabriken i Flor, jfr Topelius 1985:101ff; Thorman 1937; Flordal \& Brodén (1970); Nylander 2006. 


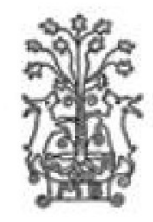

1690

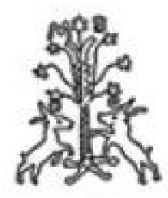

1696

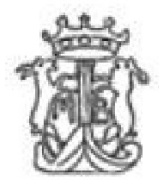

1709

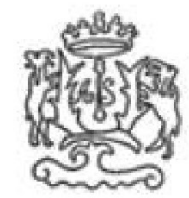

omkr.1730

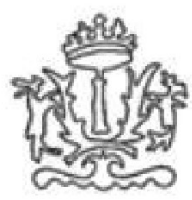

1735

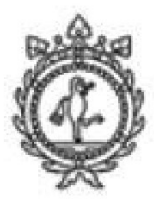

1800
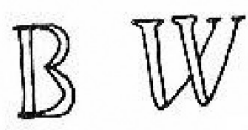

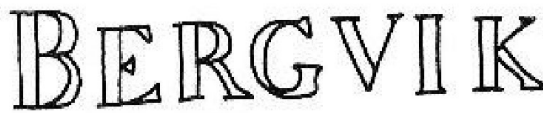

la pappret samt för att visa var det var tillverkat. Stämplar från olika bruk kan ibland urskiljas på pappret som varit underlag för måleriet. Hälsingebrukens vattenstämplar har vanligen motiv med landskapets symbol bocken i olika varianter (se fig. 3). Att hitta vattenstämplar i inredningar kräver dock demontering och ibland även destruktiva analyser för identifiering.

\section{Tillverkning av papper}

Papper av denna typ tillverkades genom en rad olika moment och steg: kokning, beredning, formning, guskning, pressning, torkning, limning och glättning. Förutom arbetsmomenten var valet av råmaterial viktigt. Papper kunde tillverkas av många olika sorters fibrer, gärna långa och fibrösa. ${ }^{16}$ Val av fibrer berodde på tillgång, ekonomi och på vilken kvalitet som önskades. Lumpen kunde innehålla lin, ull, djurhår, hampa, jute och bomull. ${ }^{117}$ Kring 1840 sker en förändring genom att papper inte längre tillverkas av lump, utan av växtfibrer och senare även träfibermassa. Nedan följer en beskrivning av hur papperstillverkning kunde gå till genom de olika momenten i tillverkningsprocessen.

116. I Asien användes bastfibrer som till exempel kozo, gampi och mitsumata. I Europa har fibrer från textillump varit vanliga råmaterial.

117. Bomull har dock använts för mer exklusiva papperskvaliteter och har inte varit lika vanlig i Sverige.
Figur 3 (3.2.3): Vattenmärken från Östanå, bild från Valeur 2006:19.

Figur 4 (3.2.4): Vattenmärke från Bergvik, bild från Bergström 1981:35. 
Steg 1: Kokning av fibrer

- Lumpen blandas med vatten, kokas och ångas. Vid kokningen löses vattenlösliga ämnen samt kemiska bindningar i fiberbuntar och fibrösa delar upp. Om råmaterialet består av växt- eller träfibrer tillförs kaustiksoda som är basisk. Basen bidrar till att lignin och vedartade ämnen, som är syrahaltiga, bryts ned. Papper som tillverkas av lump kokas inte med kaustiksoda eftersom lignin saknas då den redan är borttvättad.

\section{Steg 2: Beredning av mäld}

- De kokade fiberbuntarna i vattenlösningen mals sedan ned så att fibrerna separeras till mindre beståndsdelar, fibrer. Fibermassan kallas nu mäld eller papperspulp. Malningen sker med hjälp av en holländare - en kvarn med vassa metallblad som drivs av vattenkraft.

Steg 3: Formning av ark

- Mälden hälls i stora vattenkar och rörs om för att bli homogen. Det är viktigt att mälden innehåller rätt mängd fibrer i förhållande till vatten. En träram med ett fastspänt, glesvävt, nät (även kallad vira) på undersidan förs försiktigt, i vinkel, ned i karet för att samla upp mälden. Ramen lyfts sedan rakt upp ur karet och hålls i en vågrät position så att vattnet silas bort. Därefter skakas den lätt så att fibrernas struktur och riktning formas. Riktningen på fibrerna är beroende av hur skakningarna har utförts, i sidled eller fram och tillbaka. Mälden formas på detta sätt till ett ark.

Steg 4: Guskning

- Guskning innebär att det våta arket stjälps av från träramens nät mot en välvd guskbräda. Detta moment utförs i en framåtriktad, välvande rörelse med skjuts som får arket att släppa. Mellan arken på guskbrädan läggs fuktiga filtar som skiljer arken åt. Om arken är för tunna riskeras veck att bildas eller att de fastnar på filtarna. 
Steg 5: Pressning

- Arken pressas tillsammans med filtmellanläggen med hjälp av en stor tryckpress, så att så mycket som möjligt av vattnet försvinner. Ytterligare pressning kan göras efter steg 6: torkning.

Steg 6: Torkning

- Pappersarken hängs upp på linor eller stänger placerade $\mathrm{i}$ taket på verkstaden. Detta moment ger veck i arken som kan vara synliga även efter ytterligare pressning.

\section{Steg 7: Limning}

- Det torra arket limmas med djur- eller växtlim, harts och alun. Limningen kan ske både genom att limmet blandas direkt i mälden och/eller genom att limmet påförs i efterhand. Momentet isolerar pappret och minskar uppsugningsförmågan, det blir mindre poröst. Ett hårt limmat papper kan vara svårt att skriva på eftersom bläcket inte fäster. Efter limningen torkas arken igen.

\section{Steg 8: Glättning}

- Glättning innebär att pappersarket gnuggas med en glättsten så att det blir blankare. På så sätt skapas ett ark som är mera lämpat för tryck. Detta moment lämpar sig inte för papper som ska ha en bevarad och tydlig gräng.

Viktiga generella kunskaper för pappershantverkaren var att läsa av konsistens och tjocklek för att i rätt ögonblick i varje moment i processen kunna genomföra rörelser med precision. Det moment som var mest tidskrävande och tungt vid manuell papperstillverkning var beredningen av mälden, det vill säga malningen av fibrerna om en vattendriven kvarn inte fanns för detta. Formnings- och guskningsmomentet krävde dessutom erfarenhet, uppmärksamhet och fingertoppskänsla. Formningen i sin tur krävde dessutom noggrannhet och balans. Ifall droppar hamnade på ytan kunde ljusa prickar uppstå på det färdiga, torkade arket. Att guska av ett vått ark krävde därtill en stadig och följsam hand. Detta för att kunna avgöra hur stor press som behövdes mot guskbrädan. För att tillverka ett ark med önskvärd struktur och tjocklek 
behövde hantverkaren besitta kunskap om arkets fibrer och vad som krävs för materialets bearbetning i varje steg.

\section{Referenser}

\section{Otryckta källor}

Loos kommunarkiv. Olof Perssons arkiv, Fågelsjö socken.

\section{Tryckta källor}

Bergström, Yngve (1981). Industriorten Bergvik: gamla dokument berättar. Söderhamn: Bergvik och Ala AB.

Bringéus, Nils-Arvid (1999). Kistebrev tryckta iJönköping. Jönköping: Jönköpings läns museum.

Fiebranz, Rosemarie (2002). Jord, linne eller träkol? Genusordning och hushållsstrategier, Bjuråker 1750-1850. Diss. Uppsala: Uppsala universitet.

Flordal, Per \& Märta Brodén (1970): Flor-damastens historia (1969). Hälsingerunor 1970 , s. $140-157$.

Lemire, Beverly (2011). Cotton. Oxford: Berg Publishers.

Lundell, Jan (1981). Flors linnemanufaktori: människor och arbete vid en textilfabrik $i$ Hälsingland under åren 1729-1845. Hudiksvall: Hälsinglands museum.

Lundqvist, Pia (2008). Marknad på väg: den västgötska gårdfarihandeln 1790-1864. Diss. Göteborg: Göteborgs universitet.

Lundell, Jan \& Kerstin Sinha (1996). Bild på bondevägg. Hudiksvall: Hälsinglands museum.

Nyberg, Klas \& Pia Lundqvist (red.) (2013). Dolda innovationer: textila produkter och ny teknik under 1800-talet. Stockholm: Kulturhistoriska bokförlaget.

Nylander, Lars (2006). Den stora ekonomiska katastrofen vid Flors linnemanufaktur 1768 . Hälsingerunor 2006.

Nylén, Anna-Maja (1995). Hemslöjd: den svenska hemslöjden fram till 1800-talets slut. 4 uppl. Stockholm: Cordia.

Nyström, Ingalill (2012). Bonadsmåleri under lupp. Spektroskopiska analyser av färg och teknik isydsvenska bonadsmålningar 1700-1870. Diss. Göteborg: Göteborgs universitet, Tillgänglig på: http://hdl.handle.net/2077/30154

Palmsköld, Anneli (2016). Craft, crochet and heritage. I: Palmsköld, Anneli, Johanna Rosenqvist \& Gunnar Almevik (red.). Crafting Cultural Heritage. Göteborg: Göteborgs universitet, Institutionen för kulturvård.

Palmsköld, Anneli (2017). Den omoraliska virkningen. I: Jönsson, Lars-Eric (red.). Politiska projekt, osäkra kulturarv: en inledning [elektronisk resurs]. Lund: Lunds universitet. Tillgänglig på: http://portal.research.lu.se/ws/files/31170650/Politiska_projekt_antologi_webb.pdf

Paludan, Lis (1986). Hakling: historie og teknik. Köpenhamn: Borgen.

Rudin, Bo (1987). Papperets historia: studier i ett gammalt hantverk. Vällingby: Rudin. 
Skoglund, Git (2016). Hampa: det vita guldet. Textilväxten cannabis sativa. Möklinta: Gidlunds.

Thorman, Elisabeth (1937). Duktyger i damast från Flors manufaktur. Gefle.

Topelius, Ann-Sofi (1985). Damastduktyg och verksamheten vid Vadstena fabrik 17531843. Diss. Stockholm: Stockholms universitet.

Valeur, Christian (2007). Papper och massa i Hälsingland och Gästrikland: från handpappersbruk till processindustri. Stockholm: Skogsindustrierna.

Yafa, Stephen (2006). Cotton: The biography of a revolutionary fiber. New York: Penguin. 